\title{
Effect of Recurrent Sediment Resuspension-Deposition Events on Bioavailability of Polycyclic Aromatic Hydrocarbons in Aquatic Environments
}

\author{
Jianwei Dong ${ }^{\mathrm{a}}$, Xinghui Xia ${ }^{\mathrm{a}^{*}}$, Minghu Wang ${ }^{\mathrm{b}}$, Hui Xie ${ }^{\mathrm{a}}$, Jiaojiao Wen ${ }^{\mathrm{a}}$, Yimeng Bao ${ }^{\mathrm{a}}$ \\ ${ }^{a}$ State Key Joint Laboratory of Environment Simulation and Pollution Control, Key Laboratory \\ for Water and Sediment Sciences of Ministry of Education, School of Environment, Beijing \\ Normal University, Beijing 100875, China \\ ${ }^{\mathrm{b}}$ Aishan Hydrological Station, Hydrology and Water Resources Survey Bureau of the Shandong \\ Province, Yellow River Conservancy Commission, Shandong, 252216, China
}

${ }^{*}$ Corresponding author. Tel.: +86 10 58805314; fax: +86 1058805314.

E-mail address: xiaxh@ bnu.edu.cn (X.Xia) 


\section{Abstract}

To investigate the effect of recurrent sediment resuspension-deposition events (RSRDEs) on bioavailability of polycyclic aromatic hydrocarbons (PAHs) in aquatic environments, a modified device was used to simulate three resuspension-deposition events with the sediment collected from the Yellow River. The results showed that the dissolved organic carbon (DOC)-water distribution coefficients of PAHs decreased with time during the first resuspension-deposition period. It indicates that some PAHs associated with organic carbon $(\mathrm{OC})$ in suspended sediment (SPS) desorbed with the release of OC and became DOC-associated PAHs in the overlying water, then the PAHs desorbed from the DOC and became freely dissolved. After first 2-h suspension, only $1.90 \%$ of phenanthrene, $2.98 \%$ of pyrene, and $0.33 \%$ of chrysene in the overlying water came from pore-water; at least $61.6 \%, 89.6 \%$, and $95.3 \%$ came from DOC-associated PAHs in SPS and the rests were released from the insoluble OC in SPS. The maximum desorption ratios in the original sediment were $20 \%, 12 \%$, and $14 \%$ for phenanthrene, pyrene, and chrysene, respectively during the first resuspension-deposition event. The SPS concentration followed the sequence of the third > second > first resuspension event. This was because RSRDEs changed the SPS particle size and enhanced floc formation. There was no significant difference in the total dissolved PAH concentrations among the three resuspension events, while their freely dissolved concentrations followed the sequence of the third $>$ second $>$ first resuspension event. During deposition periods, more than half of the total/freely dissolved PAHs released during suspension still existed in the overlying water after 70-h deposition. This study suggests that the RSRDEs will increase the bioavailability of PAHs in aquatic environments, especially near the sediment-water interface, and the potential effects of PAHs during RSRDEs on fish/human in rivers and lakes should be considered in future management.

Keywords: Suspended sediment, Polycyclic aromatic hydrocarbons, Hydrophobic organic compounds, Bioavailability, Freely dissolved concentration 


\section{Introduction}

Hydrophobic organic compounds (HOCs) have a high affinity to suspended and deposited sediments in aquatic environments. Fine-grained bottom sediments can accumulate HOCs and act as an important sink for HOCs, thus reducing the bioavailability of HOCs to aquatic organisms (Lai et al., 2015; Xia et al., 2013; Zhang et al., 2014). However, once the sediment is disturbed, the resuspended particle will enter into the overlying water and may release contaminants, resulting in HOC being bioavailable in the overlying water. Therefore, sediment resuspension would exert great influences on HOC concentrations and water quality in aquatic environments (Dong et al., 2015; Friedman et al., 2009; Huang et al., 2015; Pusceddu et al., 2005; Superville et al., 2015).

Sediment resuspension is a ubiquitous process in aquatic environments (Schoellhamer, 1996). It occurs when shear stress (friction of the water against the bottom) is high enough to move the surface sediment particles (Tengberg et al., 2003). Sediment resuspension event can be caused by waves (Ferré et al., 2008), storms (Siadatmousavi and Jose, 2015), currents (Ferré et al., 2008), dredging (Je et al., 2007), trawling (Durrieu de Madron et al., 2005; Pusceddu et al., 2005), ship traffic (Superville et al., 2015), and the operation of water conservancy projects (Dong et al., 2015). All these factors, especially anthropogenic activities, often occur regularly, leading to recurrent resuspension-deposition of sediment.

Three major hydrodynamic factors influencing sediment resuspension are duration, magnitude, and frequency of resuspension. Among them, the roles of sediment resuspension duration (Feng et al., 2008; Ståhlberg et al., 2006) and magnitude (Qian et al., 2011; Ståhlberg et al., 2006; Wang et al., 2009; Wang and Yang, 2010) have been studied comprehensively. However, the effect of resuspension frequency has been less understood and most researches focused on single resuspension or re-deposition event (Chalhoub et al., 2013; Kalnejais et al., 2007; Wang and Yang, 2010; Yang et al., 2008). Sediment resuspension-deposition often occurs repeatedly in 
river and lake systems. Based on the results reported by Schoellhamer (1996), the typical duration for most types of sediment resuspension event is hours, and sediment resuspension occurs hourly to weekly. Furthermore, the effect of recurrent sediment resuspension on water quality might be different from single resuspension event. For example, during the operations of trawling and ship traffic, the bottom sediments resuspend and release contaminants into overlying water. After that, the suspended sediments (SPS) deposite as a "new" layer on the surface of bottom sediments, which is different from the original surface layer of the bottom sediments. Once the hydrodynamic condition in the water-sediment systems is changed, the deposited sediment (the new layer) will resuspend again, and the effect of the second suspension event on the water quality and HOC concentrations may be different from the effect of the first suspension event.

However, very little work has been conducted to study the effect of recurrent sediment resuspension-deposition events (RSRDEs) on the HOC concentrations in aquatic environments. Only some researchers suggested that the effect of quiescent time between resuspension events on HOC release was significant (Schneider et al., 2007; Superville et al., 2015). In addition, the previous research mainly focused on the effect of sediment resuspension on HOC concentrations in the overlying water. Few researches have been reported on the variations of HOC bioavailability during the sediment resuspension-deposition events, which can reflect their bioaccumulation in and toxic potential to aquatic organisms.

Polycyclic aromatic hydrocarbons (PAHs), a class of HOCs, are recognized as chemicals of high concern due to their extensive sources, persistence, and potentially toxic effects on ecosystems and human health, and they are ubiquitous in aquatic environments (Liu et al., 2010; Xia et al., 2015; Zhang et al., 2014). Therefore, the PAHs including phenanthrene, pyrene, and chrysene were selected as a typical kind of HOCs to investigate the effect of RSRDEs on the bioavailability of HOCs in aquatic environments. Water and sediment samples were collected near the Xiaolangdi Dam of the Yellow River, the largest turbid river in the world. Three 
sediment resuspension-deposition events were conducted with these samples through using a modified turbulence-simulation device. The freely dissolved concentrations were used to indicate the bioavailability of PAHs. Both the freely and total dissolved concentrations of the three PAHs in the overlying water among the three resuspension and deposition events were compared. The concentration, particle size, and composition of SPS were analyzed, and the relative contributions of PAHs released from SPS and from pore-water to those in the overlying water during the first resuspension-deposition event were estimated. In addition, the physicochemical mechanisms (such as the desorption/re-sorption of PAHs as well as their equilibrium between SPS and water) regarding the variations in PAH bioavailability during the RSRDEs were also explored.

\section{Materials and methods}

\subsection{Chemicals and glassware}

Three standard PAHs (phenanthrene, pyrene, and chrysene) and three deuterated PAHs (d10-phenanthrene, d10-pyrene, and d12-chrysene) were purchased from JT Baker (Philipsburg, NJ, USA). The physical-chemical properties of the studied PAHs are listed in Table S1 (Supplementary data). The internal standard ( $m$-terphenyl) and the recovery standard (2-fluorobiphenyl) were obtained from J\&K Scientific Ltd. (New Haven, C.T., USA). Other HPLC grade solvents including dichloromethane (DCM), methanol and hexane, were supplied by JT Baker (Philipsburg, NJ, USA). All glassware was pretreated as follows: soaked in an acid solution for $24 \mathrm{~h}$, afterward washed with tap water, distilled water, and ultrapure water in sequence; then dried in an oven $\left(105^{\circ} \mathrm{C}\right)$ and heated at $450^{\circ} \mathrm{C}$ in a muffle furnace for $4 \mathrm{~h}$.

\subsection{Sediment collection and pretreatment}

The 0-10 $\mathrm{cm}$ surface sediment samples were collected from the Yellow River near the Xiaolangdi Dam $\left(112^{\circ} 26^{\prime} 46.5^{\prime \prime} \mathrm{E}, 34^{\circ} 55^{\prime} 18.5^{\prime \prime} \mathrm{N}\right)$ in July 2013 using a Van Veen stainless steel grab sampler (Eijkelamp, Netherlands). The macroscopic gravel and macrofauna in the wet 
sediment were removed. Then parts of the homogenized wet sediment were used to analyze the physical-chemical properties and PAH concentrations in sediment and in pore-water. The physical-chemical properties of the sediment including particle size, composition, total organic carbon (TOC) content, black carbon (BC) content, and water content were determined. The sediment was first ground with agate mortar to pass through a 100 mesh stainless steel sieve. TOC contents in sediment were measured by an elemental analyzer (Vario El, Elementar Analysensysteme $\mathrm{GmbH}$, Germany) after treated with $\mathrm{HCl}(1: 1, \mathrm{v} / \mathrm{v})$. BC contents were determined with the chemo-thermal oxidation method. Inorganic carbon in samples was firstly removed by $\mathrm{HCl}(1: 1, \mathrm{v} / \mathrm{v})$; amorphous organic carbon was subsequently removed in a thermal oxidation procedure at $375^{\circ} \mathrm{C}$ in a tube furnace for $24 \mathrm{~h}$ in the presence of excess air. Then BC content in sediments was also determined with the elemental analyzer. The particle size of samples was determined with a Microtrac S3500 Laser Particle Size Analyzer (Microtrac Inc., Montgomeryville, PA). Due to the sandy nature of the sediment (Fig. 2), sediment pore-water was directly obtained by the filtering of the supernatants formed within minutes using $0.45-\mu$ m nylon syringe filters without the aid of a centrifuge. Possible effect of the nylon filters on aqueous PAHs was considered and no significant effect was found based on the determination of freely dissolved PAH concentrations before and after filtration. The PAH concentrations in the pore-water and sediment were determined in triplicate. In addition, another part of the wet sediment was sieved successively through $300 \mu \mathrm{m}, 150 \mu \mathrm{m}$, and $50 \mu \mathrm{m}$ sieves, then the sediment was classified into four categories: $>300 \mu \mathrm{m}, 150-300 \mu \mathrm{m}, 50-150 \mu \mathrm{m}$, and $0-50 \mu \mathrm{m}$. The four categories were freeze-dried for 72-h prior to extraction.

\subsection{Sediment resuspension experiment}

The sediment resuspension simulation was conducted with a turbulence simulation device (Fig. 1). This device consists of a vertical acrylic cylinder $(60 \mathrm{~cm}$ height and $25 \mathrm{~cm}$ diameter) and a set of oscillating vibratory grids driven by a variable speed motor (Wang et al., 2009). A total of 
$1 \mathrm{~kg}$ (wet weight) sediment was added into the cylinder. The ultrapure water $(20 \mathrm{~L})$ with $0.2 \mathrm{~g} / \mathrm{L}$ $\mathrm{NaN}_{3}$ (avoiding microorganism activities) was slowly injected into the cylinder to avoid disturbing the sediment. Then the cylinder was covered with a lid and kept under a static condition for 7 days. During sediment suspension, the perforated grids were oscillated with vertical amplitude of $3.2 \mathrm{~cm}$ (between 5.0 and $8.2 \mathrm{~cm}$ above from the sediment surface), and they were driven by the speed motor with $150 \mathrm{rpm}$, corresponding to $6.4 \mathrm{~N} / \mathrm{m}^{2}$, which was in the range of erosion shear stress $\left(0.2-75 \mathrm{~N} / \mathrm{m}^{2}\right)$ found in natural rivers (Babaeyan-Koopaei et al., 2002; Keevil et al., 2015; Kimiaghalam et al., 2015; Krishnappan and Marsalek, 2002; Reungoat et al., 2014). Furthermore, the experimental parameters including water depth and the sediment thickness used in this study are similar to other simulation experiments (Feng et al., 2008; Schneider et al., 2007).

Each sediment suspension event in this study lasted two hours, and the interval between two suspension events was 7 days. The experimental schedule is shown in Fig. S1. During each sediment suspension events, water samples were collected from three sampling ports (high, middle, and low) at the end of each suspension ( 2 h, 172 h, and 342 h). As shown in Fig. 1, the distances between the bottom of the device and the three sampling ports were 45,25 , and $5 \mathrm{~cm}$, respectively. During each sediment deposition event, the water samples were collected in triplicate at intervals $(4 \mathrm{~h}, 8 \mathrm{~h}, 26 \mathrm{~h}, 47 \mathrm{~h}$, and $70 \mathrm{~h}$ after each suspension) (Fig. S1). After collected, all the samples were centrifuged at $4000 \mathrm{rpm}$ for $20 \mathrm{~min}$ as soon as possible to separate SPS from water samples, and each of the supernatant of the water sample was collected into a conical flask (100 ml) after centrifugation for PAH analysis. The SPS was freeze-dried, and then its mass and distributions of particle size were determined. In addition, the TOC content in the SPS collected during the first suspension period was determined with an elemental analyzer (Vario El, Elementar Analysensysteme GmbH, Germany). The SPS samples during sediment deposition were not much enough for the determination of particle size. The dissolved organic 
carbon (DOC) of the supernatant was also determined with an elemental analyzer (Vario El, Elementar Analysensysteme GmbH, Germany).

\subsection{PAH extraction and determination}

\subsubsection{Determination of freely dissolved PAH concentration}

Usually, the total dissolved HOCs are operationally defined as the HOCs which can pass through a $0.45 \mu \mathrm{m}$ filter. The freely dissolved HOCs, commonly adopted to characterize the bioavailability, are defined as the HOCs that are dissolved in the aqueous phase alone and in no way bound to any matrix (Pawliszyn, 1999). So the total dissolved HOCs include both the freely dissolved and the part combined with small colloids and DOC. Polyethylene device (PED) was used to determine the freely dissolved PAH concentrations in overlying water and pore-water. Details of the method were described in our previous research (Dong et al., 2013; Xia et al., 2013). Briefly, the polyethylene (PE) sheets (low density, 51 $\pm 3 \mu \mathrm{m}$ thick, Carlisle Plastics, Inc., Minneapolis, MN) were cut into small strips $(\sim 1.5 \mathrm{mg})$ before use. Then they were soaked in DCM for $48 \mathrm{~h}$, followed by methanol for $48 \mathrm{~h}$, and finally rinsed with ultrapure water and soaked in ultrapure water for $48 \mathrm{~h}$. After that, approximately $30 \mathrm{~g}$ PE were allowed to equilibrate with 3 $\mathrm{L}$ of performance reference compound solution (i.e. d10-phenanthrene, d10-pyrene, and d12-chrysene, each at a concentration of $10 \mu \mathrm{g} / \mathrm{L}$ ) for at least three months before use.

For the determination of freely dissolved PAH concentrations, one PE strip was suspended centrally in each conical flask fill with the supernatant of water sample. After deployment for 8 hours, each strip was rinsed with ultrapure water and dried. The results showed that the mass adsorbed in the PED achieved a depletion ratio of $3.9 \%$ of the freely dissolved PAH concentration in the water phase, which was less than $5 \%$ and could be considered negligible. For the determination of PAHs in the PE strips, one strip was placed into a new conical flask containing $10 \mathrm{ml} \mathrm{DCM}$ and $50 \mu \mathrm{l}$ recovery standard $(1 \mu \mathrm{g} / \mathrm{ml})$; then all the flasks were sealed and 
shaken on a horizon shaker for $24 \mathrm{~h}\left(30^{\circ} \mathrm{C}, 120 \mathrm{rpm}\right)$. Each strip was extracted with DCM (10 ml) for three times and the extracts were combined. Afterwards, the combined extract was concentrated with a rotary evaporator and solvent exchanged with hexane. The final extracts were blown to $1 \mathrm{ml}$ under nitrogen in a graduated test tube followed by addition of $50 \mu \mathrm{l}$ meta-terphenyl $(1 \mu \mathrm{g} / \mathrm{ml})$ as an internal standard before GC/MS analysis. Details of GC/MS analysis are shown in Supplementary Information (SI 1.1).

\subsubsection{Determination of total dissolved PAH concentration}

The total dissolved PAHs in the overlying water and pore-water samples were extracted by solid-phase extraction (SPE) using Oasis HLB cartridges (Waters, Milford, MA, USA), which were pre-conditioned with $10 \mathrm{ml} \mathrm{DCM}, 4 \mathrm{ml}$ methanol, and $4 \mathrm{ml}$ ultrapure water successively before extraction. A total of $100 \mathrm{ml}$ filtered water sample with $5 \mathrm{ng}$ 2-fluorobiphenyl was transferred to a $100 \mathrm{ml}$-conical flask, and $5 \mathrm{ml}$ methanol were added to enhance PAH extraction recoveries. Then the water sample in each flask was passed through a SPE cartridge at a speed of $5 \mathrm{ml} / \mathrm{min}$. After that, all the cartridges were subject to freeze-drying for over $72 \mathrm{~h}$ until totally dried. Then the PAHs in each cartridge were eluted three times with $6 \mathrm{ml}$ DCM each time. The eluents were combined, concentrated, and solvent-exchanged to $1 \mathrm{ml}$ hexane under a soft nitrogen stream. Then a total of $50 \mu \mathrm{l}$ meta-terphenyl $(1 \mu \mathrm{g} / \mathrm{ml})$ was added into each sample prior to GC/MS analysis (SI 1.1).

\subsubsection{Determination of PAH concentration in the original sediment}

The PAH concentrations in original sediment and the four fractions $(>300 \mu \mathrm{m}, 150-300 \mu \mathrm{m}$, 50-150 $\mu \mathrm{m}$, and 0-50 $\mu \mathrm{m}$ ) of the sediment were determined with an accelerated solvent extractor (ASE300, Dionex Corp., USA). A total of $2 \mathrm{~g}$ (dry weight) samples with $100 \mu 1$ 2-fluorobiphenyl $(1 \mu \mathrm{g} / \mathrm{ml})$ were extracted twice under $100{ }^{\circ} \mathrm{C}$ and $1500 \mathrm{psi}$, using $66 \mathrm{ml}$ hexane-acetone $(1: 1, \mathrm{v} / \mathrm{v})$ for each time. Then the total extract was concentrated by a rotary evaporator and solvent 
exchanged with $5 \mathrm{ml}$ of hexane before the clean-up procedure. The detail of the clean-up procedure can be found in our previous study (Liu et al., 2010). Briefly, clean up was carried out on a silica gel-alumina column of $10 \mathrm{~mm}$ diameter. Activated silica gel, alumina, and anhydrous sodium sulfate were successively filled into the column till the height of $12 \mathrm{~cm}, 6 \mathrm{~cm}$, and $1 \mathrm{~cm}$, respectively. The extracted sample was then loaded onto the prepared silica gel-alumina column. Elution was performed by successively loading $15 \mathrm{ml}$ hexane and $70 \mathrm{ml}$ hexane-dichloromethane $(3: 7, \mathrm{v} / \mathrm{v})$ and the second part of the elution was collected for PAH determination. The elution was again concentrated and solvent exchanged with hexane. After that, samples were concentrated below $1 \mathrm{ml}$ under a nitrogen stream followed by the addition of $100 \mu \mathrm{l}$ meta-terphenyl $(1 \mu \mathrm{g} / \mathrm{ml})$ prior to GC/MS analysis (SI 1.1).

\subsection{Quality assurance/quality control}

The correlation coefficients for PAH calibration curves with GC/MS were all higher than 0.99 . The method detection limits of the phenanthrene, pyrene, and chrysene in water samples were 0.9, 0.5, and $0.4 \mathrm{ng} / \mathrm{L}$, respectively. The PAHs in blank SPE cartridges were below detection limits. As shown in Table S1, the recoveries of phenanthrene, pyrene, and chrysene in spiked solution ranged from $79.6 \%$ to $104.9 \%(\mathrm{~N}=15)$. The recovery of 2-fluorobiphenyl (recovery standard) ranged from $66.9 \%$ to $90.9 \%$ in water samples, from $67.1 \%$ to $87.6 \%$ in sediment samples, and from $60.0 \%$ to $78.9 \%$ in polyethylene samples. All the data were corrected with the recoveries of recovery standard. All samples were in triplicate, and the results are expressed as average \pm standard deviation.

\section{Results and discussion}

\subsection{SPS characteristics during RSRDEs}

The characteristics of the original sediment and SPS are listed in Fig. 2 and Fig. S2. The particle sizes of original sediment used in this study were comparable to those collected from 
other rivers for sediment resuspension research (Alkhatib and Weigand, 2002; Feng et al., 2008). Furthermore, the SPS concentrations of this study were comparable to those obtained in sediment resuspension simulation experiments with other river sediments (Hudjetz et al., 2014; Wang et al., 2009) and the levels during a flood event in other rivers (Eyrolle et al., 2012). Although the resuspension strength $\left(150 \mathrm{rpm}, 6.4 \mathrm{~N} / \mathrm{m}^{2}\right.$ ) was constant among the three resuspension events, the SPS concentrations followed the sequence of the first $<$ the second $<$ the third resuspension event for all sampling ports. For example, for the middle sampling port, the SPS concentration increased from $6.78 \pm 0.03 \mathrm{~g} / \mathrm{L}$ during the first resuspension event to $9.36 \pm 0.10 \mathrm{~g} / \mathrm{L}$ during the second resuspension event and to $10.8 \pm 0.11 \mathrm{~g} / \mathrm{L}$ during the third resuspension event. This is because during the first deposition event, the SPS deposited as a new layer with a loose crumb structure upon the bottom sediment. Then they could easily suspend during the subsequent resuspension events. Furthermore, dynamic flocculation processes might take place during the resuspension-deposition events, and the formed flocs with a diameter of 22-182 um have relatively low densities (Guo and $\mathrm{He}, 2011$ ); it is easy for them to enter into the overlying water once sediment resuspension occurs again. This could be supported by the data that particles with a size of 50-150 $\mu \mathrm{m}$ were more abundant during the second and third resuspension events (Fig. 2). For example, the percentage of the particles with a size of $50-150 \mu \mathrm{m}$ for the high sampling port increased from $53.4 \%$ during the first resuspension to $62.5 \%$ during the second resuspension and to $69.6 \%$ during the third resuspension. Therefore, more sediment could be suspended during the second and third resuspension events, resulting in higher SPS concentrations. In addition, during sediment deposition events, the SPS concentrations decreased to approximately $0.01 \mathrm{~g} / \mathrm{L}$ after 70-h deposition for all sampling ports (Fig. S2).

The particle size of the SPS during the three resuspension events was below $300 \mu \mathrm{m}$, and the average percentages of clay $(<2 \mu \mathrm{m})$, silt $(2 \sim 50 \mu \mathrm{m})$, fine sand $(50 \sim 150 \mu \mathrm{m})$, and coarse sand $(>150 \mu \mathrm{m})$ of the SPS were $0 \pm 0 \%, 31.9 \pm 9.6 \%, 63.6 \pm 9.1 \%$, and $4.49 \pm 2.3 \%$, respectively. The 
particle size of all the SPS samples was smaller than that of the original sediment used in this study $\left(<500 \mu \mathrm{m}\right.$, as shown in Fig. 2). This is because the shear stress $\left(6.4 \mathrm{~N} / \mathrm{m}^{2}\right)$ used in this study was not high enough to suspend the particles with a size of $>300 \mu \mathrm{m}$. In addition, it also might be due to that the flocs were breaking up in suspension with the high shear stress. In addition, the particle size distribution of the SPS varied among the three resuspension events; both the concentration and percentage of smaller particles with a size of $<50 \mu \mathrm{m}$ followed the sequence of the first $>$ second $>$ third resuspension event (Fig. 2). This is due to that the RSRDEs make the smaller particles with a size of $<50 \mu \mathrm{m}$ aggregate and form flocs. Therefore, the above results suggest that RSRDEs will change the particle size of SPS.

For each sediment resuspension-deposition event, the SPS concentration at the low sampling port was the highest, followed by the concentrations at the middle and the high sampling ports (Fig. 2). Wang et al. (2009) showed that SPS concentration in the bottom water was higher than that in the surface water in the simulation experiments conducted with a similar device to this study. Also, the result obtained in this study was consistent with the SPS distribution in natural rivers reported by Luo et al. (2004) and Bianchi et al. (2002); they indicated that the SPS concentration in the bottom water was higher than the level in the surface water of the Pearl River and the lower Mississippi River, respectively.

\subsection{PAH concentrations during the first sediment resuspension-deposition event}

\subsubsection{Total and freely dissolved PAH concentrations}

The variations of total and freely dissolved PAH concentrations during the first resuspension-deposition event are shown in Fig. 3. Before the resuspension event, the PAH concentrations in the overlying water were approximately zero. During the resuspension period, the PAH concentrations in the overlying water increased due to the fact that both pore-water 
release and bottom sediment suspension released PAHs into the overlying water. Interestingly, at the beginning of deposition period, although the SPS concentration decreased, the PAH concentrations in the overlying water increased further, and reached maximum values after deposition for $4 \mathrm{~h}$. This is because the resuspension duration ( $2 \mathrm{~h}$ ) was not long enough to bridge the gap of PAHs between the contaminated sediment and overlying water, and the SPS with larger particle sizes would still release PAHs during settling. After 4-h deposition, both the total and freely dissolved PAH concentrations decreased sharply with time. This was resulted from the re-sorption of PAHs in the water phase by the smaller SPS particles with large specific surface areas (Chalhoub et al., 2013; Dong et al., 2015; Feng et al., 2008). The PAH concentrations in the overlying water decreased slightly with time after 8-h deposition and remained relatively unchanged after 26-h deposition due to the very low SPS concentration (Fig. S2).

Both the total and freely dissolved concentrations of the three PAHs at the low sampling port were the highest, followed by the concentrations at the middle and high sampling ports during the first sediment resuspension event (Fig. 3), and this was also true for most samples during the deposition event. The results were consistent with that obtained in the field reported by some researchers (Ko and Baker, 1995; Luo et al., 2004; Zeng et al., 2005); they found that there was significant difference in total/freely dissolved HOC concentrations between the surface water and bottom water. Fernandez et al. (2012) reported that the freely dissolved concentrations of DDT congeners in the bottom water were approximately six times higher than those in the surface water in the vicinity of a marine superfund site on the Palos Verdes Shelf.

\subsubsection{Contribution of freely to total dissolved PAH concentrations}

During resuspension period, the contribution ratios of freely to total dissolved concentrations of phenanthrene, pyrene, and chrysene were $35.4 \% \pm 12.1 \%, 8.2 \% \pm 1.5 \%$, and $1.5 \% \pm 0.4 \%$, respectively. During deposition period, the contribution ratios were $64.8 \% \pm 13.1 \%, 17.3 \% \pm 10.7 \%$, and $2.4 \% \pm 1.9 \%$, respectively. The DOC concentrations during resuspension period were higher 
than those during deposition period (Fig. S2), leading to more PAHs associated with DOC or colloids during resuspension period. Therefore, the ratios of freely to total dissolved PAH concentrations during deposition period were higher than those during resuspension period. In addition, for both resuspension and deposition periods, the sequence of the ratios was phenanthrene > pyrene > chrysene; they were negatively correlated with the $\log \mathrm{K}_{\mathrm{OW}}$ (octanol-water partition coefficient) values of the three PAHs. This relationship is universal for aqueous environments and can be explained by the fact that PAH of more hydrophobic (higher $\mathrm{K}_{\mathrm{Ow}}$ value) has a higher affinity for the small particles and DOC in river water, leading to a lower freely dissolved concentration (Xia et al., 2013).

\subsection{Sources of PAHs and OC in the overlying water during the first sediment resuspension-deposition event}

\subsubsection{Distributions of PAHs between DOC/SPS and water phases}

The distribution coefficients $\left(\mathrm{K}_{\mathrm{DOC}}, \mathrm{L} / \mathrm{kg}\right)$ of PAHs between DOC and water phases in the overlying water can be calculated with the following equation during sediment resuspension-deposition event:

$$
K_{D O C}=\frac{C_{T W}-C_{F W}}{C_{F W} \times[D O C]} \times 10^{6}
$$

where $\mathrm{C}_{\mathrm{TW}}$ and $\mathrm{C}_{\mathrm{FW}}$ are the total and freely dissolved $\mathrm{PAH}$ concentrations in overlying water (ng/L), respectively; [DOC] is the DOC concentration in the overlying water $(\mathrm{mg} / \mathrm{L})$. According to the equation above, the $\mathrm{K}_{\mathrm{DOC}}$ values during each resuspension event could be estimated. The result shown in Table $\mathrm{S} 2$ indicated that the sequence of the $\mathrm{K}_{\mathrm{DOC}}$ values of the three PAHs was phenanthrene $<$ pyrene $<$ chrysene, and the log $\mathrm{K}_{\mathrm{DOC}}$ values were positively correlated with their $\log \mathrm{K}_{\mathrm{OW}}$ values. 
As shown in Fig. 3, PAHs kept releasing into the overlying water during the first $6 \mathrm{~h}$ of the sediment resuspension-deposition event. For the high sampling port, the $\log \mathrm{K}_{\mathrm{DOC}}$ values of the three PAHs at 6-h were lower than those at 2-h (Table S2), indicating that PAHs desorbed from DOC into the overlying water. This suggested that during resuspension event, some PAHs associated with OC in SPS desorbed with the release of OC and became DOC-associated PAHs in the overlying water, then the PAHs desorbed from the DOC and became freely dissolved. If PAH desorption and OC desorption from the SPS occurred separately, the desorbed PAHs from the SPS would be re-sorbed by the desorbed OC in the overlying water, leading to the increase of the $\mathrm{K}_{\mathrm{DOC}}$ values, which obviously contradict the result shown in Table $\mathrm{S} 2$.

The PAHs in the overlying water during resuspension-deposition including three parts: freely dissolved, DOC-associated, and SPS-associated, and the mass balance of PAHs in this system could be expressed as follows.

$$
C_{S e d} \times[S P S]_{i} \times V=C_{F W i} \times V+[D O C]_{i} \times K_{D O C i} \times C_{F W i} \times V \times 10^{-6}+[S P S]_{i} \times K_{P i} \times C_{F W i} \times V \times 10^{-3}
$$

where $\mathrm{V}$ is the water volume $(20 \mathrm{~L})$ in this system; $\mathrm{C}_{\mathrm{Sed}}$ is the PAH concentration in the original sediment with a particle size of $0-300 \mu \mathrm{m}$ before resuspension because particles with a size of $>300 \mu \mathrm{m}$ can't suspend as mentioned in section $3.1(\mathrm{ng} / \mathrm{g}) ;[\mathrm{SPS}]_{i}$ is the SPS concentration in the overlying water during the $i^{\text {th }}$ resuspension event $(\mathrm{g} / \mathrm{L}) ; \mathrm{C}_{\mathrm{FW} i}$ is the freely dissolved PAH concentration in the overlying water during the $i^{\text {th }}$ resuspension event (ng/L); $\mathrm{K}_{\mathrm{P} i}$ is SPS-water distribution coefficient of PAHs during the $i^{\text {th }}$ resuspension event $(\mathrm{L} / \mathrm{kg})$. According to this equation, the $\mathrm{K}_{\mathrm{P}}$ values of the three PAHs calculated with their freely dissolved concentrations during each resuspension event could be estimated. Similar to the $\log \mathrm{K}_{\mathrm{DOC}}$ values, the $\log \mathrm{K}_{\mathrm{P}}$ values of the three PAHs at 6-h were lower than those at 2-h during the first resuspension-deposition event (Table S2). Because PAHs in SPS were mainly sorbed by OC of the SPS, as mentioned above, some PAHs associated with OC desorbed with the release of OC, leading to the decrease of $\mathrm{K}_{\mathrm{P}}$ values. In addition, some PAHs might also desorb from insoluble 
OC in the SPS and become freely dissolved, and this might be another reason for the decrease of $K_{P}$ values.

\subsubsection{Contributions of pore-water and sediment to PAHs in the overlying water}

The release of contaminants in the overlying water is primarily derived from an upward mixing of pore-water and contaminant desorption from SPS. The mass balance of total dissolved PAHs in the overlying water during the first resuspension period could be expressed as follows.

$$
C_{T W} \times\left(V+V_{P}\right)=M_{P W \text {-releaese }}+M_{D O C-\text { release }}+M_{P O C \text {-release }}
$$

where $\mathrm{V}_{\mathrm{P}}$ is the volume $(\mathrm{L})$ released by pore-water into the overlying water; $M_{P W-\text { release }}$ is the amount of PAHs released from pore-water, including freely dissolved and DOC-associated; $M_{\text {DOC-release }}$ is the amount of OC-associated PAHs released from the SPS; $M_{P O C \text {-release }}$ is the amount of PAHs released from insoluble OC in the SPS. In this study, according to the SPS concentration $(6.3 \pm 1.6 \mathrm{~g} / \mathrm{L}$, on average $)$ in the overlying water during the first resuspension event, about $127 \mathrm{~g}$ (dry weight) sediment suspended and became SPS. The water content in the original sediment was $17.27 \pm 1.63 \%$. Therefore, approximately $26.5 \mathrm{ml}$ of pore-water was mixed with 20-L overlying water during sediment resuspension. According to the total dissolved PAH concentrations in the overlying water during the first resuspension event, there were $5.04 \mathrm{mg}$ phenanthrene, $1.69 \mathrm{mg}$ pyrene, and $1.60 \mathrm{mg}$ chrysene released into the overlying water.

The amount of PAHs released from pore-water could be calculated with the following equation:

$$
M_{P W-\text { release }}=C_{T W-P} \times V_{P}
$$

where $\mathrm{C}_{\mathrm{TW}-\mathrm{P}}$ is total dissolved PAH concentration in the pore-water before resuspension $(\mathrm{ng} / \mathrm{L})$. In this study, approximately $26.5 \mathrm{ml}$ of pore-water were mixed with 20-L overlying water during sediment resuspension and only $95.8 \mathrm{ng}$ phenanthrene, $50.4 \mathrm{ng}$ pyrene, and $5.35 \mathrm{ng}$ chrysene 
were released from the pore-water. Thus, the pore-water contributed to $1.90 \%, 2.98 \%$, and $0.33 \%$ of phenanthrene, pyrene, and chrysene in the overlying water during the first resuspension event, respectively (Table S3). Morin and Morse (1999) showed that about two thirds of the ammonia released from sediment suspension originated from desorption rather than dilution of pore-water. Schneider et al. (2007) studied the sediment resuspension with the Hudson River sediment, and found that the release of polychlorinated biphenyls (PCBs) from pore-water is considered to be instantaneous, and its contribution is much smaller than the contribution of contaminant desorption from SPS. Feng et al. (2008) also indicated that most of released contaminants in the overlying water were contributed to the release from resuspended sediment collected from the Yangtze River, which was consistent with our results obtained in this study.

According to the results shown in section 3.3.1, some PAHs associated with OC in SPS desorbed with the release of OC and became DOC-associated PAHs in the overlying water, then the PAHs desorbed from the DOC. Therefore, the amount of DOC-associated PAHs desorbed from the SPS into the overlying water could be estimated as follows.

$$
M_{D O C-\text { release }} \geq\left(C_{T W}-C_{F W}\right) \times\left(V+V_{P}\right)-\left(C_{T W-P}-C_{F W-P}\right) \times V_{P}
$$

where $\mathrm{C}_{\mathrm{FW}-\mathrm{P}}$ is the freely dissolved $\mathrm{PAH}$ concentration in the pore water before resuspension (ng/L). Therefore, $\left(C_{T W}-C_{F W}\right) \times\left(V+V_{P}\right)$ is the difference between the total and freely dissolved PAHs in the overlying water, which was equivalent to the sum of DOC-associated PAHs released from the pore-water and the SPS. According to the results after 2-h resuspension, the DOC-associated PAHs released from the soluble OC in the SPS contributed to at least $61.6 \%$, $89.6 \%$, and $95.3 \%$ of the total amounts of phenanthrene, pyrene, and chrysene in the overlying water, respectively (details of the calculation are described in SI 1.2). Because PAHs in the SPS were mainly sorbed by OC of the SPS, in addition to the pore-water and the soluble OC in the 
SPS, the rests (approximately $36.5 \%$ of phenanthrene, $7.42 \%$ of pyrene, and $4.37 \%$ of chrysene) were released from the insoluble OC of the SPS (Table S3).

In addition, as shown in Fig. 3, the PAH concentrations in the overlying water at 6-h reached their maximum values during the first resuspension-deposition event. Therefore, the maximum desorption amounts of phenanthrene, pyrene, and chrysene from the SPS during the first resuspension-deposition event could be estimated at $67.1 \mathrm{ng} / \mathrm{g}, 19.0 \mathrm{ng} / \mathrm{g}$, and $16.1 \mathrm{ng} / \mathrm{g}$, respectively. Compared with their concentrations in the original sediment before resuspension, approximately $20 \%$ of phenanthrene, $12 \%$ of pyrene, and $14 \%$ of chrysene in the original sediment desorbed and released into the overlying water. Schneider et al. (2007) indicated that approximately $22 \%$ of PCBs in the resuspended sediment collected from the Hudson River were released into the overlying water after $2 \mathrm{~h}$ resuspension, which was consistent with our result. However, Chalhoub et al. (2013) reported that only 0.04\% of PCBs desorbed from the sediment collected from Lake Bourget (France) during 1-h sediment resuspension in a simulation experiment. This might be due to shorter suspension time and lower SPS concentrations (less than $200 \mathrm{mg} / \mathrm{L}$ ) in their study.

Similar to the PAH release during the first suspension period, the release of OC into the overlying water is ascribed to pore-water release and desorption from SPS. According to the DOC concentrations in the overlying water $(2.55 \pm 1.86 \mathrm{mg} / \mathrm{L})$ and the pore-water $(5.2 \mathrm{mg} / \mathrm{L})$, the pore-water contributed to $0.27 \%$ of the DOC in the overlying water, and less than $5 \%$ of the OC in the SPS were soluble (details of the calculation are described in SI 1.3). This was consistent with the result reported by Sun et al. (2009) that only $2 \%$ of OC in the sediment of the Yellow River was soluble.

\subsection{PAH concentrations during RSRDEs}

\subsubsection{Total dissolved PAH concentrations during RSRDEs}


As shown in Fig. 7, after the first resuspension-deposition, the PAH concentrations in the overlying water remained relatively unchanged but they were still high from 28 -h to $72-\mathrm{h}$. During the second resuspension period, the deposited sediment resuspended again and released PAHs into the overlying water, leading to the increase of PAHs in the overlying water. During the second deposition period, PAHs in the overlying water were re-sorbed by the settling SPS, resulting in the sharp decrease of the $\mathrm{PAH}$ concentrations in the water phase. After 26-h deposition, the PAH concentrations in the overlying water almost kept constant. This is also true for the third resuspension-deposition period.

There was no significant difference in the total dissolved concentrations of the three PAHs among the three resuspension events ( $\mathrm{p}>0.05$ ) (Fig. 4). For example, the total dissolved phenanthrene concentrations at the high sampling port during the first, second, and third resuspension events were $197 \pm 8.9 \mathrm{ng} / \mathrm{L}, 179 \pm 67.3 \mathrm{ng} / \mathrm{L}$, and $187 \pm 41.9 \mathrm{ng} / \mathrm{L}$, respectively. Both the SPS concentration and SPS particles with a size of 50-150 $\mu \mathrm{m}$ followed the sequence of the first $<$ second < third resuspension event (Fig. 2); this might affect the desorption and re-sorption of PAHs during RSRDEs, leading to the similar PAH concentrations in the overlying water among the three resuspension-deposition events. In addition, similar to the vertical distribution of their concentrations during the first resuspension-deposition event, the total dissolved concentrations of the three PAHs at the low sampling port were the highest, followed by the middle and high sampling ports during the second and third resuspension-deposition events (Fig. 4 and Fig. 5).

During the RSRDEs, there was no significant difference in the total dissolved concentrations of the three PAHs among the three deposition events ( $>>0.05)$ (Fig. 5). In addition, for each event, the SPS concentration was only $0.01 \mathrm{~g} / \mathrm{L}$ after $70-\mathrm{h}$ deposition. However, more than $60 \%$ of the PAHs released during resuspension period still existed in the overlying water after deposition for $70 \mathrm{~h}$ (Fig. 7). For example, for the third resuspension-deposition event, the ratios of total 
dissolved concentrations of phenanthrene, pyrene, and chrysene after 70-h deposition to their corresponding concentrations during suspension were $81 \% \pm 13 \%, 79 \% \pm 32 \%$, and $61 \% \pm 25 \%$, respectively.

\subsubsection{Freely dissolved PAH concentrations during RSRDEs}

During the three resuspension events, the freely dissolved concentrations of the three PAHs during the third resuspension event were the highest, followed by the second and first events (Fig. 4). For example, the freely dissolved phenanthrene concentrations at the middle sampling port during the first, second, and third resuspension events were $94 \pm 8.4 \mathrm{ng} / \mathrm{L}, 109 \pm 6.1 \mathrm{ng} / \mathrm{L}$, and $125 \pm 10.3 \mathrm{ng} / \mathrm{L}$, respectively. The reason could be analyzed as follows. The total dissolved PAHs included the freely dissolved part and those associated with DOC or colloids (Dong et al., 2013). For all sampling ports, the DOC concentration during the first resuspension event was the highest, followed by the second and third resuspension events (Fig. 2). Therefore, the DOC-associated PAHs followed the sequence of the first $>$ second $>$ third resuspension events. Thus, with no significant difference in the total dissolved PAH concentrations among the three resuspension events as mentioned above, the freely dissolved PAH concentrations followed the sequence of the first $<$ second $<$ third resuspension events. In addition, for all sampling ports, it could be easily found that the $K_{P}$ values of the three PAHs between SPS and water calculated with their freely dissolved concentrations during the first resuspension period were the highest, followed by the second and third resuspension periods (Table S4), suggesting that multiple suspension is needed for PAHs to reach the equilibrium between SPS and water. Furthermore, the $\log K_{P}$ values for the three PAHs were comparable to those obtained in the Yellow River during water-sediment regulation of the Xiaolangdi Reservoir (Dong et al., 2015).

Different from the resuspension events, there was no significant difference in the freely dissolved PAH concentrations among the three deposition events (Fig. 5). For both the second and third resuspension-deposition events, the total and freely dissolved concentrations in the 
overlying water after 4-h deposition were lower than those during resuspension, which was different from the situation during the first resuspension-deposition period. This is because before the second and third resuspension events, the PAH concentrations in the overlying water were about $60 \%-80 \%$ of the levels during first resuspension event (Fig. 6 and Fig. 7). Thus, 2-h sediment resuspension could easily make the PAHs in the overlying water reach their maximum values. Therefore, the total and freely dissolved concentrations in the overlying water after 4-h deposition were lower than those during resuspension period.

\subsection{Effect of RSRDEs on PAH bioavailability}

The freely dissolved concentration of HOCs is an indicator to reflect their bioavailability in aquatic systems (Bao and Zeng, 2011; Booij et al., 2003; Xia et al., 2013). In this study, although there was no significant difference in the freely dissolved concentrations of the three PAHs after 70-h deposition among the three sediment resuspension-deposition events ( $p>0.05$ ), the ratios of freely dissolved concentrations of phenanthrene, pyrene, and chrysene after 70-h deposition to their corresponding concentrations during resuspension were $82 \% \pm 48 \%, 80 \% \pm 76 \%$, and $65 \% \pm 45 \%$, respectively. That is to say, after resuspension, the freely dissolved PAHs after $70-\mathrm{h}$ deposition in the overlying water were still more than half of those during resuspension periods. It indicated that there was high bioavailable PAH concentrations in the overlying water, even after three resuspension-deposition events. This suggested that the potential risks of contaminants released from sediment during resuspension event to the fish and human beings would not disappear with the deposition of SPS, and this impact would last long ( one week) after sediment resuspension. In addition, during all resuspension events, the freely dissolved PAH concentrations at the low sampling port were higher than those at the high sampling port. For example, during the first resuspension period, the freely dissolved phenanthrene concentration for the low sampling port was approximately 3.4 times higher than the level for the high sampling port (Fig. 4). The results indicated that the potential risks of PAHs during resuspension period to 
organisms inhabited near sediment-water interface (benthic organisms) might be higher than those to organisms inhabited near surface water (planktons).

In this study, at the end of three resuspension-deposition events (412 h), about $4.7 \pm 2.2 \%$ of the PAHs associated with SPS released into the overlying water. According to our previous research (Dong et al., 2015), there were approximately $4.0 \%$ of the PAHs in the suspended sediment released into the Yellow River water during sediment regulation of the Xiaolangdi Reservoir, which was comparable to that obtained in this research. Therefore, the results obtained in this study can reflect the effects of RSRDEs on HOC bioavailability in the field. In natural waters, recurrent sediment resuspension events occur frequently, and the RSRDEs would increase the HOC bioavailability and exposure risks of HOCs to aquatic organisms and even humans.

\section{Acknowledgements}

This study was supported by the National Science Foundation for Distinguished Young Scholars (No: 51325902), National Science Foundation for Innovative Research Group (No: 51421065), and the National Science Foundation of China (No: 51279010).

\section{References}

Alkhatib, E., Weigand, C., 2002. Parameters affecting partitioning of 6 PCB Congeners in natural sediment. Environ. Monit. Assess. 78, 1-17. DOI: 10.1023/A:1016180422675

Babaeyan-Koopaei, K., Ervine, D.A., Carling, P.A., Cao, Z., 2002. Velocity and Turbulence Measurements for Two Overbank Flow Events in River Severn. J Hydraul. Eng. 128, 891-900. DOI: 10.1061/(ASCE)0733-9429(2002)128:10(891)

Bao, L., Zeng, E.Y., 2011. Passive sampling techniques for sensing freely dissolved hydrophobic organic chemicals in sediment porewater. TrAC. Trends Anal. Chem. 30, 1422-1428. DOI:10.1016/j.trac.2011.05.004

Bianchi, T.S., Mitra, S., McKee, B.A., 2002. Sources of terrestrially-derived organic carbon in 
lower Mississippi River and Louisiana shelf sediments: implications for differential sedimentation and transport at the coastal margin. Mar. Chem. 77, 211-223. DOI:10.1016/S0304-4203(01)00088-3

Booij, K., Hoedemaker, J.R., Bakker, J.F., 2003. Dissolved PCBs, PAHs, and HCB in Pore Waters and Overlying Waters of Contaminated Harbor Sediments. Environ. Sci. Technol. 37, 4213-4220. DOI: $10.1021 / \mathrm{es} 034147 \mathrm{c}$

Chalhoub, M., Amalric, L., Touzé, S., Gallé, P., Reiller, P.E., Doucet, N., Clozel, B., Bataillard, P., 2013. PCB partitioning during sediment remobilization-a 1D column experiment. J. Soil. Sediment. 13, 1284-1300. DOI: 10.1007/s11368-013-0683-5

Dong, J., Xia, X., Zhai, Y., 2013. Investigating particle concentration effects of polycyclic aromatic hydrocarbon (PAH) sorption on sediment considering the freely dissolved concentrations of PAHs. J. Soil. Sediment. 13, 1469-1477. DOI:10.1007/s11368-013-0736-9

Dong, J., Xia, X., Wang, M., Lai, Y., Zhao, P., Dong, H., Zhao, Y., Wen, J., 2015. Effect of Water-Sediment Regulation of the Xiaolangdi Reservoir on the Concentrations, Bioavailability, and Fluxes of PAHs in the Middle and Lower Reaches of the Yellow River. J. Hydrol. 527, 101-112. DOI:10.1016/j.jhydrol.2015.04.052

Durrieu de Madron, X., Ferre, B., Le Corre, G., Grenz, C., Conan, P., Pujo-Pay, M., Buscail, R., Bodiot, O., 2005. Trawling-induced resuspension and dispersal of muddy sediments and dissolved elements in the Gulf of Lion (NW Mediterranean). Cont. Shelf. Res. 25, 2387-2409. DOI:10.1016/j.csr.2005.08.002

Eyrolle, F., Radakovitch, O., Raimbault, P., Charmasson, S., Antonelli, C., Ferrand, E., Aubert, D., Raccasi, G., Jacquet, S., Gurriaran, R., 2012. Consequences of hydrological events on the delivery of suspended sediment and associated radionuclides from the Rhône River to the Mediterranean Sea. J. Soil. Sediment. 12(9), 1479-1495.

Feng, J., Shen, Z., Niu, J., Yang, Z., 2008. The role of sediment resuspension duration in release 
of PAHs. Chinese Sci. Bull. 53, 2777-2782. DOI: 10.1007/s11434-008-0389-z

Ferré, B., Durrieu de Madron, X., Estournel, C., Ulses, C., Le Corre, G., 2008. Impact of natural (waves and currents) and anthropogenic (trawl) resuspension on the export of particulate matter to the open ocean: application to the Gulf of Lion (NW Mediterranean). Cont. Shelf. Res. 28, 2071-2091. DOI:10.1016/j.csr.2008.02.002

Fernandez, L.A., Lao, W., Maruya, K.A., White, C., Burgess, R.M., 2012. Passive Sampling to Measure Baseline Dissolved Persistent Organic Pollutant Concentrations in the Water Column of the Palos Verdes Shelf Superfund Site. Environ. Sci. Technol. 46, 11937-11947. DOI: $10.1021 / \mathrm{es} 302139 y$

Friedman, C.L., Burgess, R.M., Perron, M.M., Cantwell, M.G., Ho, K.T., Lohmann, R., 2009. Comparing Polychaete and Polyethylene Uptake to Assess Sediment Resuspension Effects on PCB Bioavailability. Environ. Sci. Technol. 43, 2865-2870. DOI: 10.1021/es803695n

Guo, L., He, Q., 2011. Freshwater flocculation of suspended sediments in the Yangtze River, China. Ocean. Dynam. 61, 371-386. DOI 10.1007/s10236-011-0391-x

Huang, L., Fang, H., Fazeli, M., Chen, Y., He, G., Chen, D., 2015. Mobility of phosphorus induced by sediment resuspension in the Three Gorges Reservoir by flume experiment. Chemosphere 134, 374-379. DOI:10.1016/j.chemosphere.2015.05.009

Hudjetz, S., Herrmann, H., Cofalla, C., Brinkmann, M., Kammann, U., Schäffer, A., Schüttrumpf, H., Hollert, H., 2014. An attempt to assess the relevance of flood events-biomarker response of rainbow trout exposed to resuspended natural sediments in an annular flume. Environ. Sci. Pollut. R. 21(24), 13744-13757.

Je, C.H., Hayes, D.F., Kim, K.S., 2007. Simulation of resuspended sediments resulting from dredging operations by a numerical flocculent transport model. Chemosphere. 70, 187-195. DOI:10.1016/j.chemosphere.2007.06.033

Kalnejais, L.H., Martin, W.R., Signell, R.P., Bothner, M.H., 2007. Role of Sediment 
Resuspension in the Remobilization of Particulate-Phase Metals from Coastal Sediments. Environ. Sci. Technol. 41, 2282-2288. DOI: 10.1021/es061770z

Keevil, C.E., Chanson, H., Reungoat, D., 2015. Fluid Flow and Sediment Entrainment in the Garonne River Bore and Tidal Bore Collision. Earth. Surf. Proc. Land. 40, 1574-1586. DOI: 10.1002/esp.3735

Kimiaghalam, N., Goharrokhi, M., Clark, S.P., Ahmari, H., 2015. A comprehensive fluvial geomorphology study of riverbank erosion on the Red River in Winnipeg, Manitoba, Canada. J. Hydrol. 529, 1488-1498. doi:10.1016/j.jhydrol.2015.08.033

Ko, F., Baker, J.E., 1995. Partitioning of hydrophobic organic contaminants to resuspended sediments and plankton in the mesohaline Chesapeake Bay. Mar. Chem. 49, 171-188. DOI:10.1016/0304-4203(94)00064-K

Krishnappan, B.G., Marsalek, J., 2002. Modelling of flocculation and transport of cohesive sediment from an on-stream stormwater detention pond. Water Research. 36, 3849-3859. DOI:10.1016/S0043-1354(02)00087-8

Lai, Y., Xia, X., Dong, J., Lin, W., Mou, X., Zhao, P., Jiang, X., Li, Z., Tong, Y., Zhao, Y., 2015. Equilibrium State of PAHs in Bottom Sediment-Water-Suspended Sediment System of a Large River Considering Freely Dissolved Concentrations. J. Environ. Qual. 44, 823-832. DOI:10.2134/jeq2014.09.0381

Liu, S., Xia, X., Yang, L., Shen, M., Liu, R., 2010. Polycyclic aromatic hydrocarbons in urban soils of different land uses in Beijing, China: Distribution, sources and their correlation with the city's urbanization history. J. Hazard. Mater. 177, 1085-1092. DOI: 10.1016/j.jhazmat.2010.01.032

Luo, X., Mai, B., Yang, Q., Fu, J., 2004. Polycyclic aromatic hydrocarbons (PAHs) and organochlorine pesticides in water columns from the Pearl River and the Macao harbor in the Pearl River Delta in South China. Mar. Pollut. Bull. 48, 1102-1115. 
DOI:10.1016/j.marpolbul.2003.12.018

Morin, J., Morse J.W., 1999. Ammonium release from resuspended sediments in the Laguna Madre estuary. Mar. Chem. 65, 97-110. DOI:10.1016/S0304-4203(99)00013-4

Pawliszyn, J., 1999. Applications of solid phase microextraction. ed. Royal Society of Chemistry, Combridge, UK, pp.129-130.

Pusceddu, A., Grémare, A., Escoubeyrou, K., Amouroux, J., Fiordelmondo, C., Danovaro, R., 2005. Impact of natural (storm) and anthropogenic (trawling) sediment resuspension on particulate organic matter in coastal environments. Cont. Shelf. Res. 25, 2506-2520. DOI: 10.1016/j.csr.2005.08.012

Qian, J., Zheng, S., Wang, P., Wang, C., 2011. Experimental study on sediment resuspension in taihu lake under different hydrodynamic disturbances. J.Hydrodyn. Ser. B. 23, 826-833. DOI: 10.1016/S1001-6058(10)60182-5

Reungoat, D., Chanson, H., Caplain, B., 2014. Sediment Processes and Flow Reversal in the Undular Tidal Bore of the Garonne River (France). Environ. Fluid. Mech. 14, 591-616. DOI: 10.1007/s10652-013-9319-y.

Schneider, A.R., Porter, E.T., Baker, J.E., 2007. Polychlorinated Biphenyl Release from Resuspended Hudson River Sediment. Environ. Sci. Technol. 41, 1097-1103. DOI: $10.1021 / \mathrm{es} 0607584$

Schoellhamer, D.H., 1996. Anthropogenic Sediment Resuspension Mechanisms in a Shallow Microtidal Estuary. Estuar. Coast. Shelf. S. 43, 533-548. DOI:10.1006/ecss.1996.0086

Siadatmousavi, S.M., Jose, F., 2015. Winter storm-induced hydrodynamics and morphological response of a shallow transgressive shoal complex: Northern Gulf of Mexico. Estuar. Coast. Shelf. S. 154, 58-68. DOI:10.1016/j.ecss.2014.12.025

Ståhlberg, C., Bastviken, D., Svensson, B.H., Rahm, L., 2006. Mineralisation of organic matter in coastal sediments at different frequency and duration of resuspension. Estuar. Coast. Shelf. S. 
70, 317-325. DOI: $10.1016 /$ j.ecss.2006.06.022

Sun, L., Sun, W., Ni, J., 2009. Partitioning of water soluble organic carbon in three sediment size fractions: Effect of the humic substances. J. Environ. Sci. 21, 113-119. DOI:10.1016/S1001-0742(09)60020-6

Superville, P-J., Prygiel, E., Mikkelsen, O., Billon, G., 2015. Dynamic behaviour of trace metals in the Deûle River impacted by recurrent polluted sediment resuspensions: From diel to seasonal evolutions. Sci. Total. Environ. 506-507, 585-593. DOI:10.1016/j.scitotenv.2014.11.044

Tengberg, A., Almroth, E., Hall, P., 2003. Resuspension and its effects on organic carbon recycling and nutrient exchange in coastal sediments: in situ measurements using new experimental technology. J. Exp. Mar. Biol. Ecol. 285-286, 119-142. DOi:10.1016/S0022-0981(02)00523-3

Wang, L., Shen, Z., Wang, H., Niu, J., Lian, G., Yang, Z., 2009. Distribution characteristics of phenanthrene in the water, suspended particles and sediments from Yangtze River under hydrodynamic conditions. J. Hazard. Mater. 165, 441-446. DOI: 10.1016/j.jhazmat.2008.10.016

Wang, L., Yang, Z., 2010. Simulation of polycyclic aromatic hydrocarbon remobilization in typical active regions of river system under hydrodynamic conditions. J. Soil. Sediment. 10, 1380-1387. DOI: 10.1007/s11368-010-0286-3

Xia, X., Zhai, Y., Dong, J., 2013. Contribution ratio of freely to total dissolved concentrations of polycyclic aromatic hydrocarbons in natural river waters. Chemosphere 90, 1785-1793. DOI: 10.1016/j.chemosphere.2012.08.021

Xia, X., Li, H., Yang, Z., Zhang, X., Wang, H., 2015. How does predation affect the bioaccumulation of hydrophobic organic compounds in aquatic organisms? Environ. Sci. Technol. 49, 4911-4920. DOI: 10.1021/acs.est.5b00071 
Yang, Z., Feng, J., Niu, J., Shen, Z., 2008. Release of polycyclic aromatic hydrocarbons from Yangtze River sediment cores during periods of simulated resuspension. Environ. Pollut. 155, 366-374. DOI:10.1016/j.envpol.2007.11.007

Zeng, E.Y., Tsukada, D., Diehl, D.W., Peng, J., Schiff, K., Noblet, J.A., Maruya, K.A., 2005. Distribution and mass inventory of total dichlorodiphenyldichloroethylene in the water column of the Southern California Bight. Environ. Sci. Technol. 39, 8170-8176. DOI: $10.1021 / \mathrm{es} 051213 \mathrm{x}$

Zhang, X., Xia, X., Dong, J., Bao, Y., Li, H., 2014. Enhancement of toxic effects of phenanthrene to Daphnia magna due to the presence of suspended sediment. Chemosphere 104, 162-169. DOI:10.1016/j.chemosphere.2013.10.086 


\section{Figure captions}

Figure 1 Turbulence simulation device used in this study

Figure 2 Particle size distributions of SPS, DOC and SPS concentrations during the three resuspension events (Original: original sediment; Clay: particles with a size of 0-2 $\mu \mathrm{m}$; Silt: particles with a size of 2-50 $\mu \mathrm{m}$; Fine sand: particles with a size of 50-150 $\mu \mathrm{m}$; Coarse sand: particles with a size of 150-500 $\mu \mathrm{m}$ for original sediment and with a size of 150-300 $\mu \mathrm{m}$ for SPS.)

Figure 3 Total and freely dissolved PAH concentrations during the first sediment resuspension-deposition event in the low, middle, and high sampling port of the turbulence simulation device

Figure 4 Freely and total dissolved PAH concentrations in the low, middle, and high sampling ports during recurrent sediment resuspension events

Figure 5 Freely and total dissolved PAH concentrations in the low, middle, and high sampling ports during recurrent sediment deposition events

Figure 6 Freely dissolved PAH concentrations during recurrent sediment resuspension-deposition events (Shadow regions stand for the suspension periods; solid circles stand for the samples collected at the end of suspension)

Figure 7 Total dissolved PAH concentrations during recurrent sediment resuspension-deposition events (Shadow regions stand for the suspension periods; solid circles stand for the samples collected at the end of suspension) 


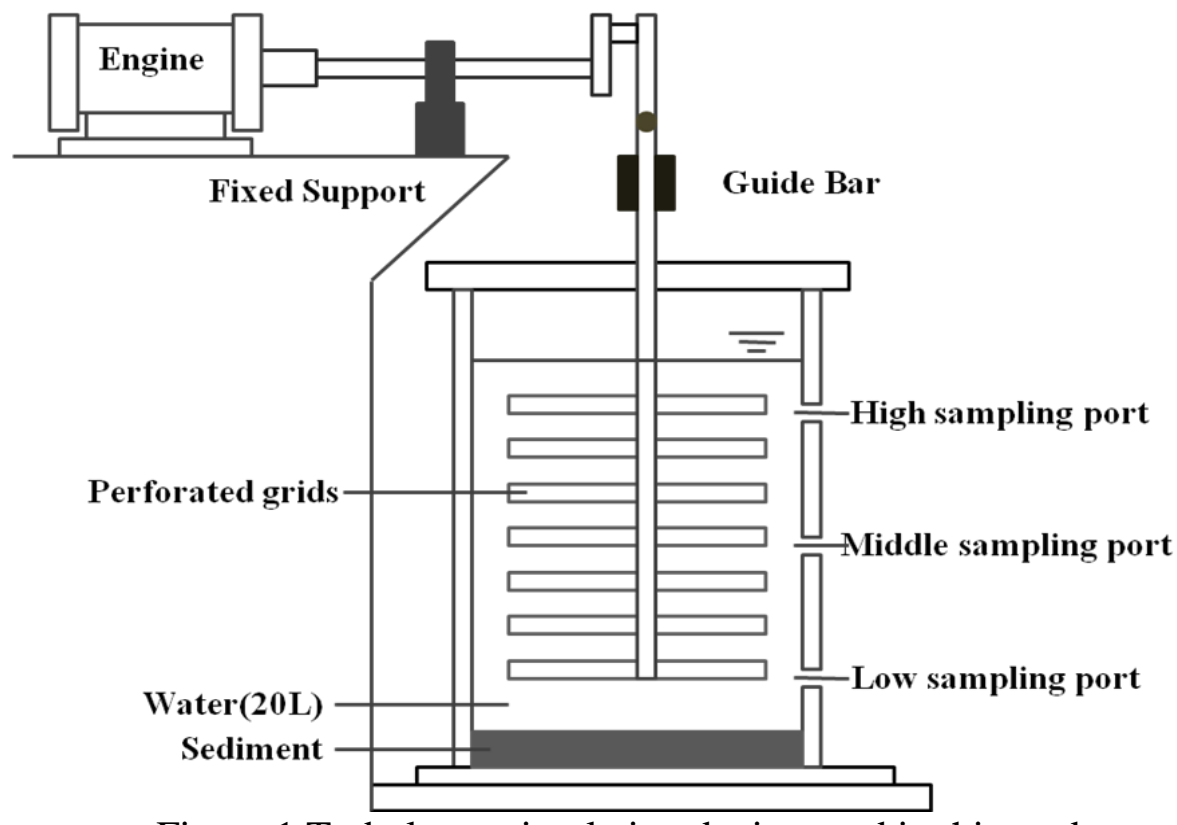

Figure 1 Turbulence simulation device used in this study 

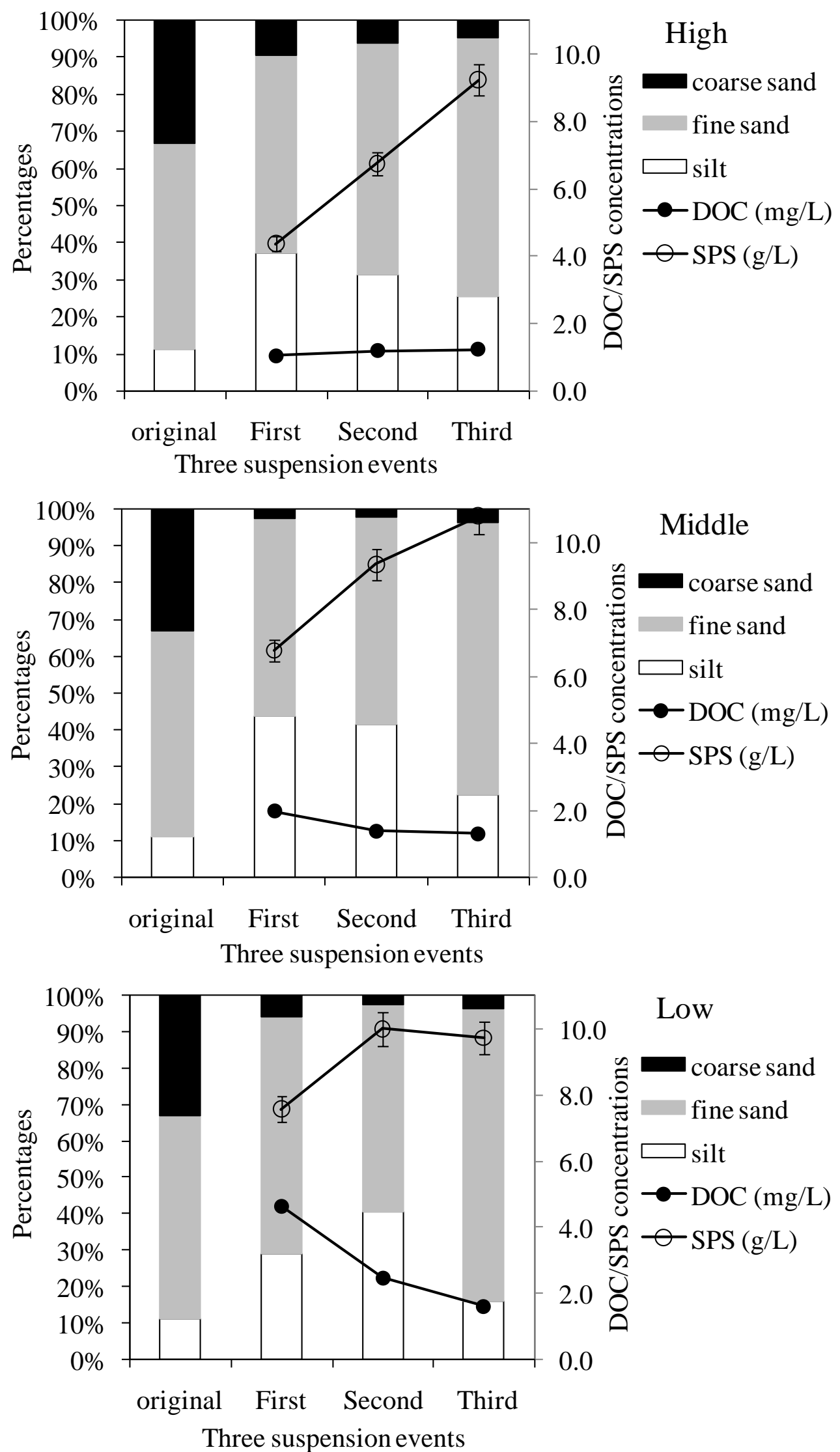

Figure 2 Particle size distributions of SPS, DOC and SPS concentrations during the three resuspension events (Original: original sediment; Clay: particles with a size of 0-2 $\mu \mathrm{m}$; Silt: particles with a size of 2-50 $\mu \mathrm{m}$; Fine sand: particles with a size of 50-150 $\mu \mathrm{m}$; Coarse sand: particles with a size of $150-500 \mu \mathrm{m}$ for original sediment and with a size of $150-300 \mu \mathrm{m}$ for SPS.) 

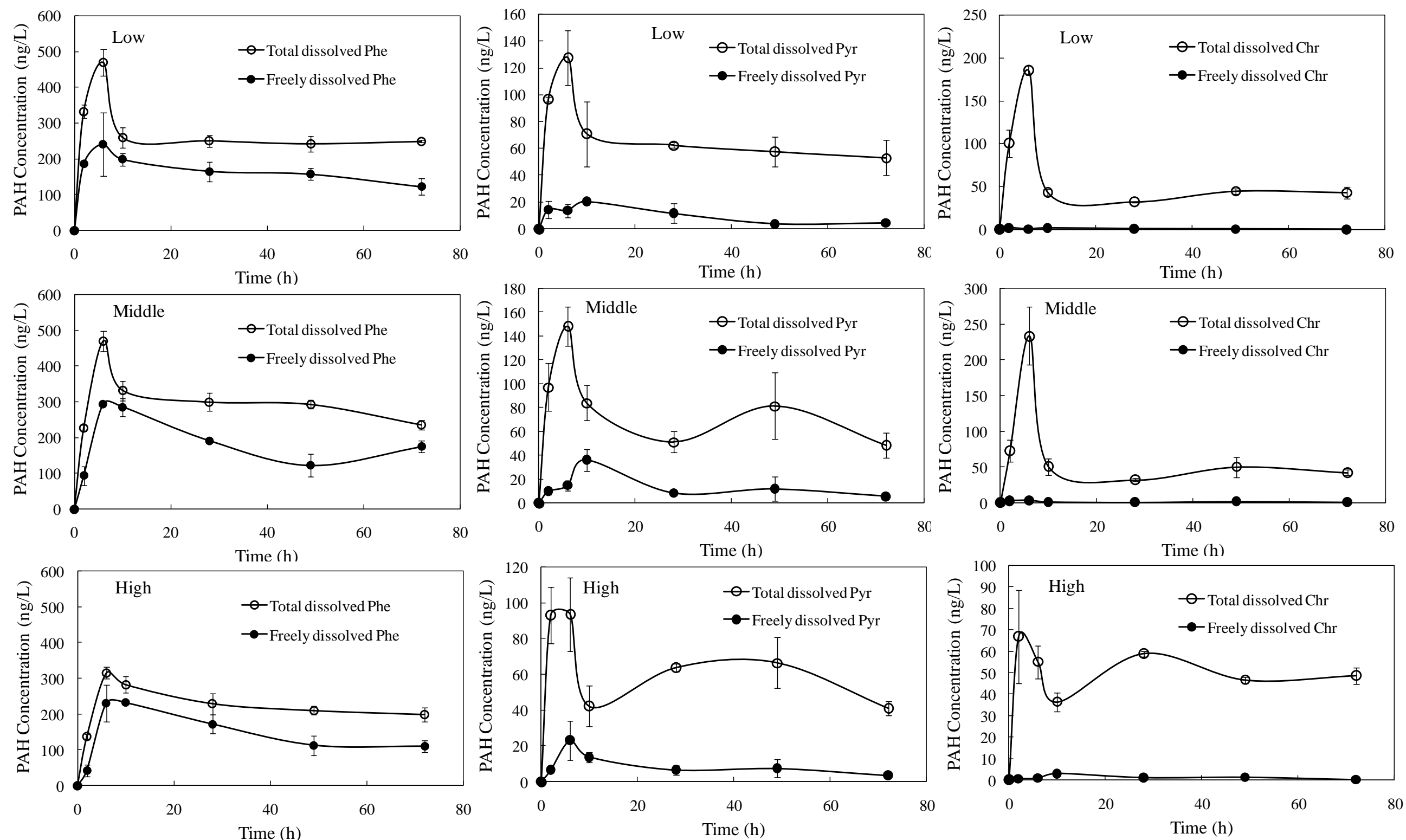

Figure 3 Total and freely dissolved PAH concentrations during the first sediment resuspension-deposition event in the low, middle, and high sampling port of the turbulence simulation device 

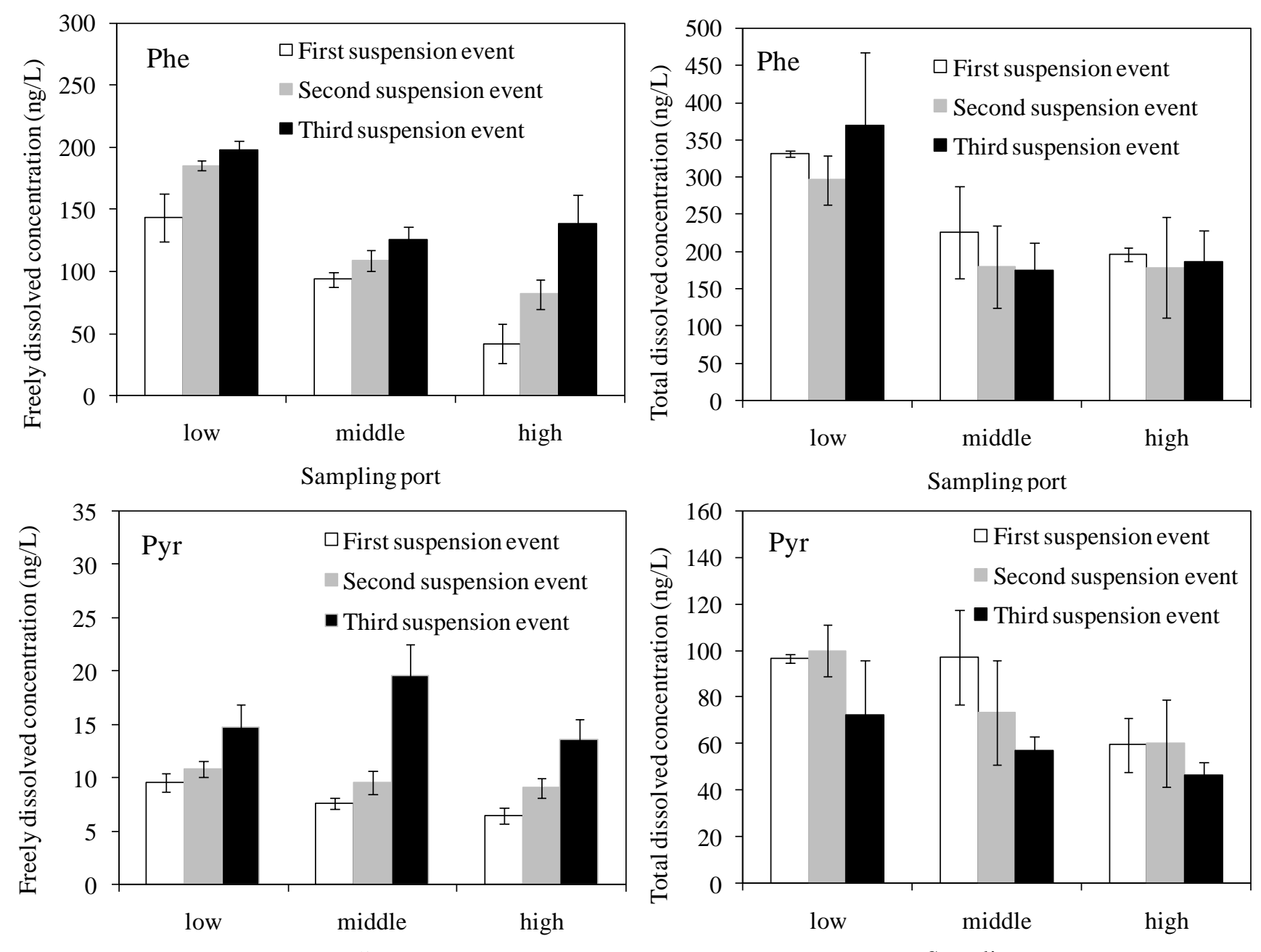

Sampling port
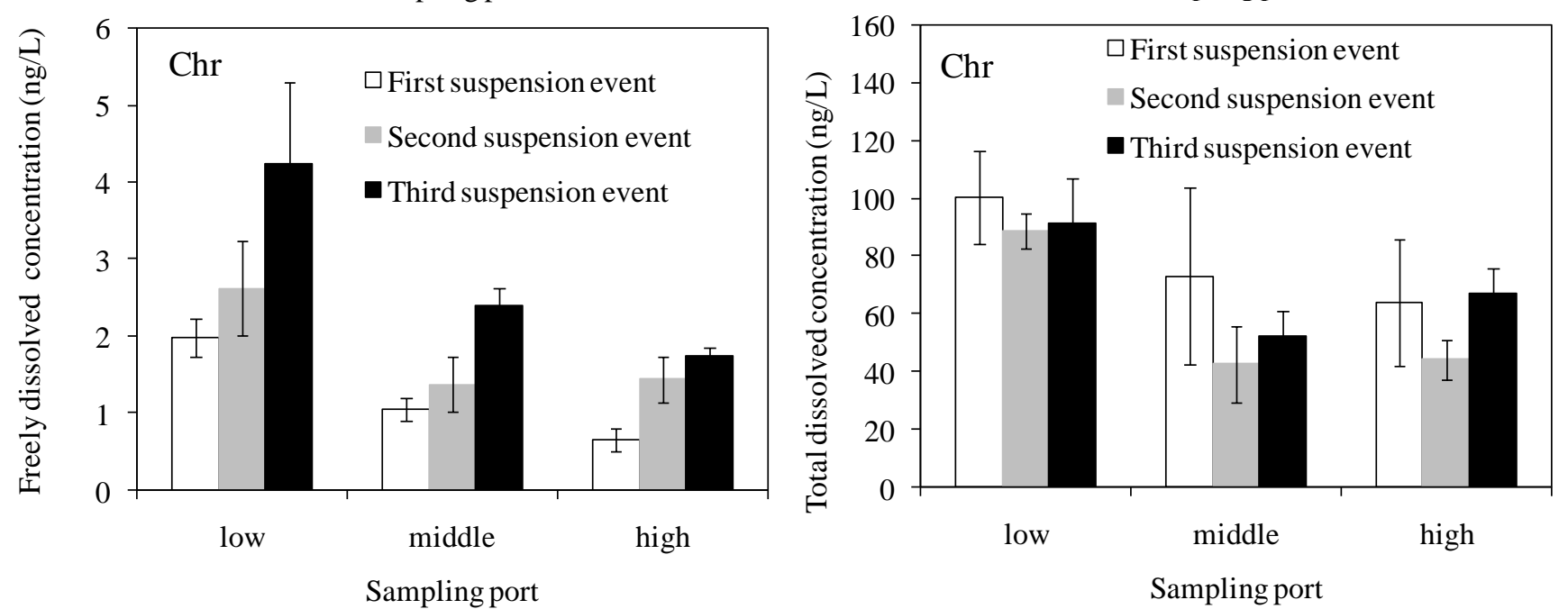

Figure 4 Freely and total dissolved PAH concentrations in the low, middle, and high sampling ports during recurrent sediment resuspension events 

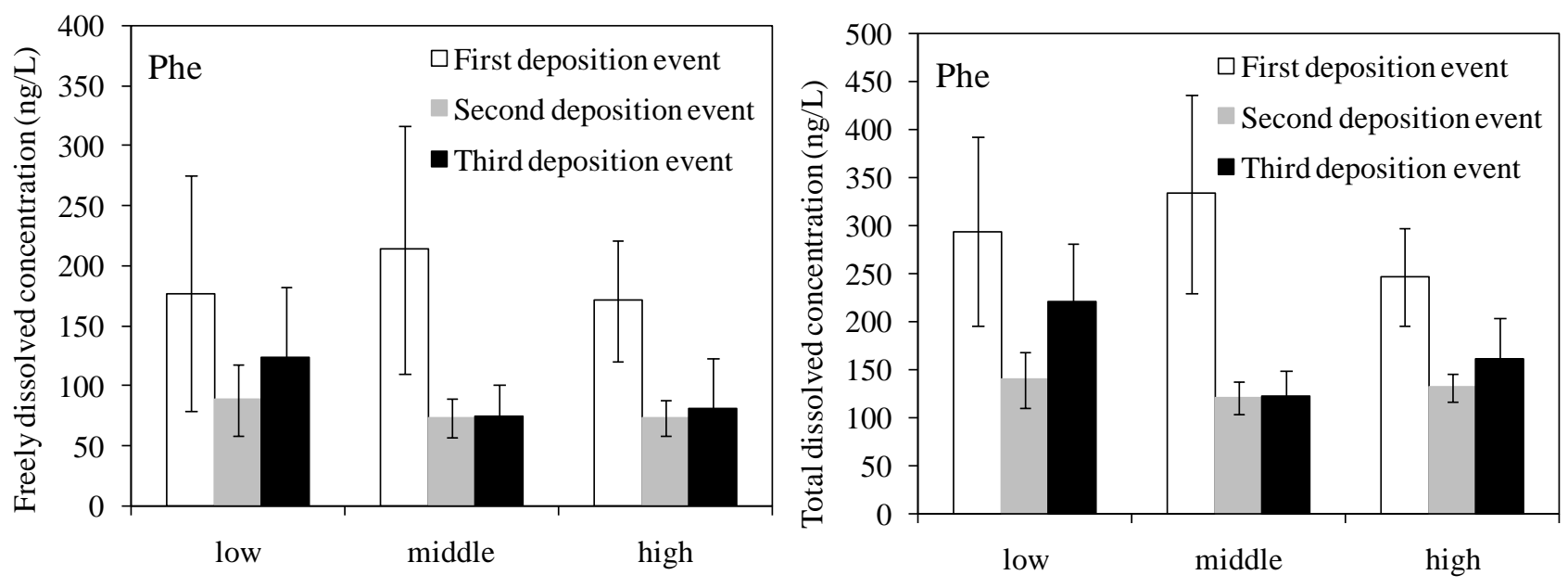

Sampling port
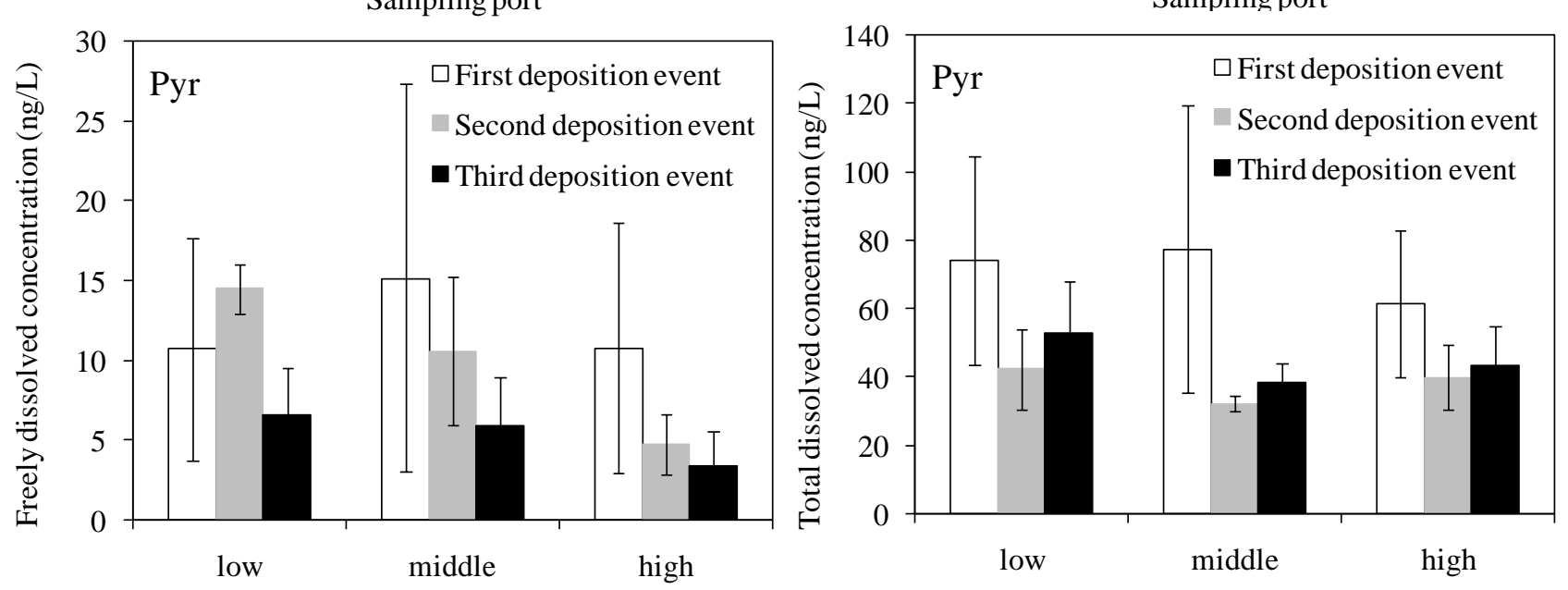

Sampling port

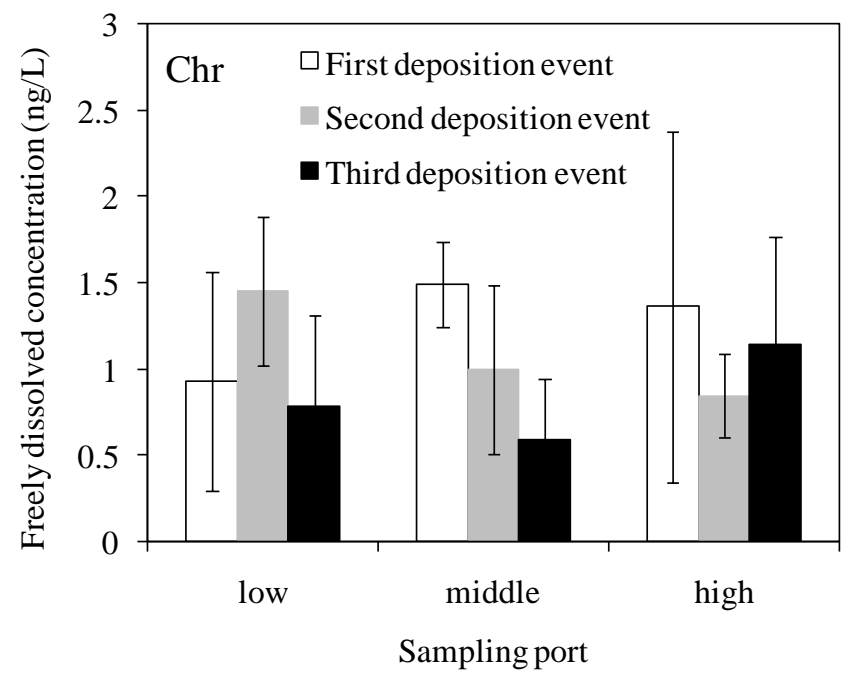

Sampling port

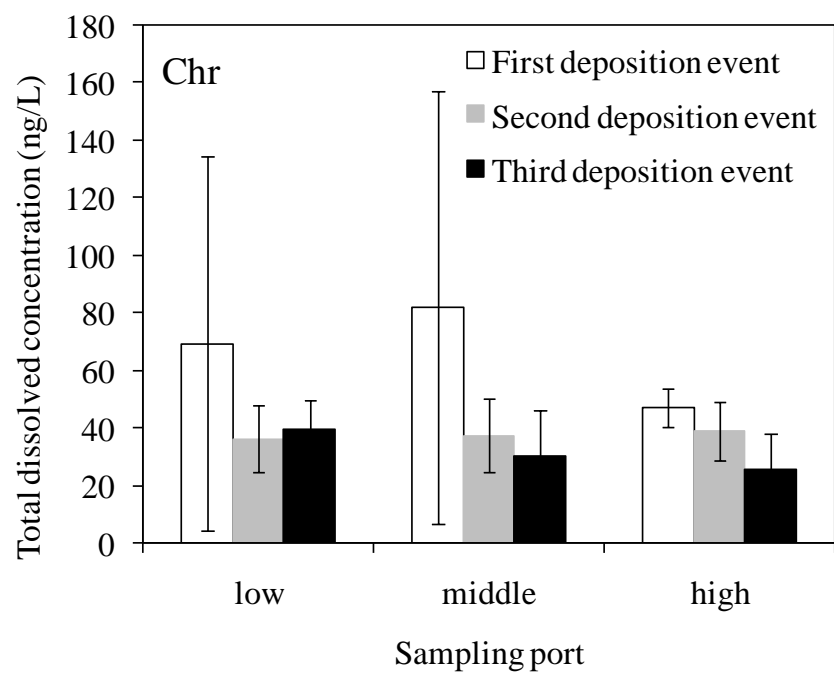

Figure 5 Freely and total dissolved PAH concentrations in the low, middle, and high sampling ports during recurrent sediment deposition events 

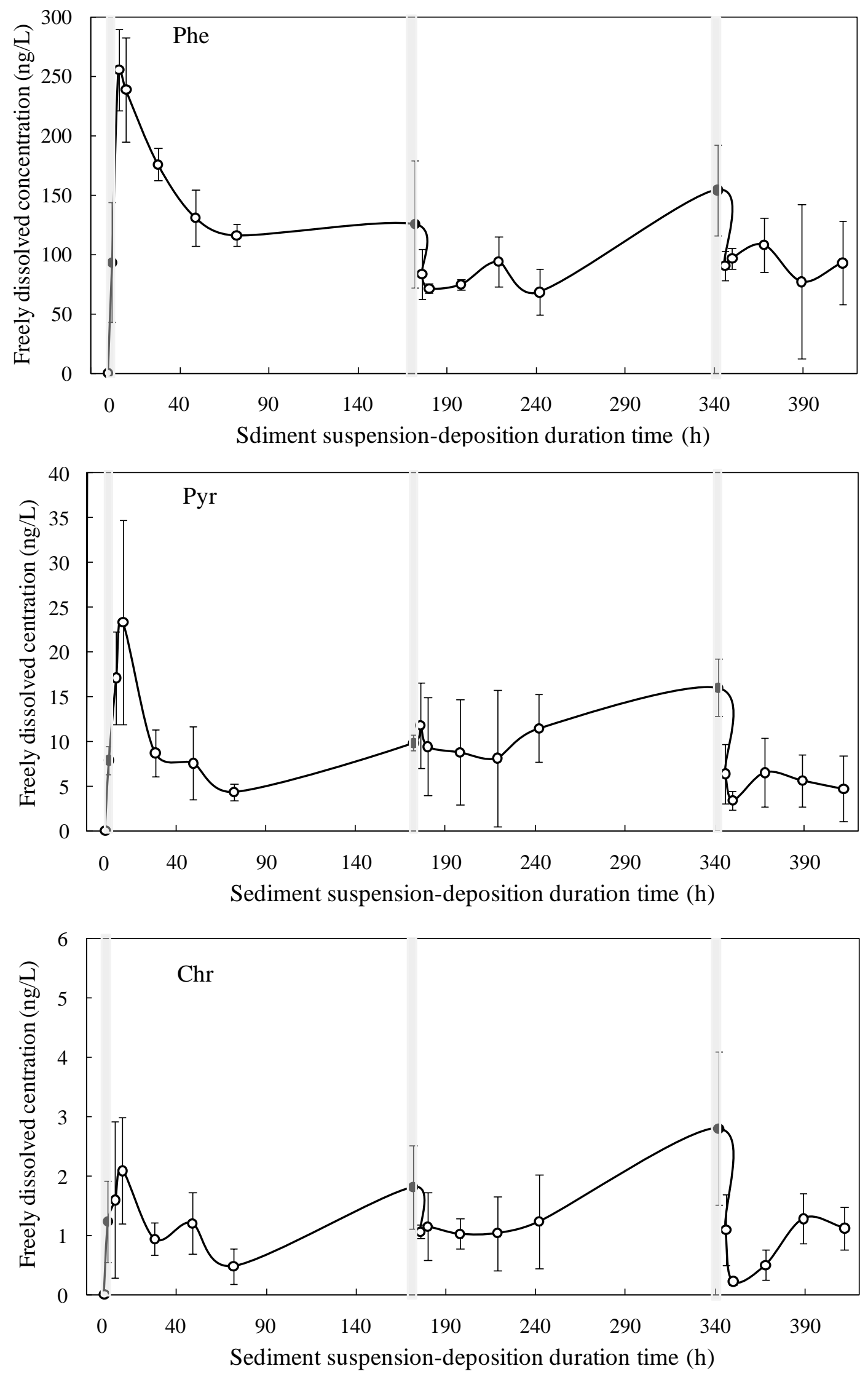

Figure 6 Freely dissolved PAH concentrations during recurrent sediment resuspension-deposition events

(Shadow regions stand for the suspension periods; solid circles stand for the samples collected at the end of suspension) 

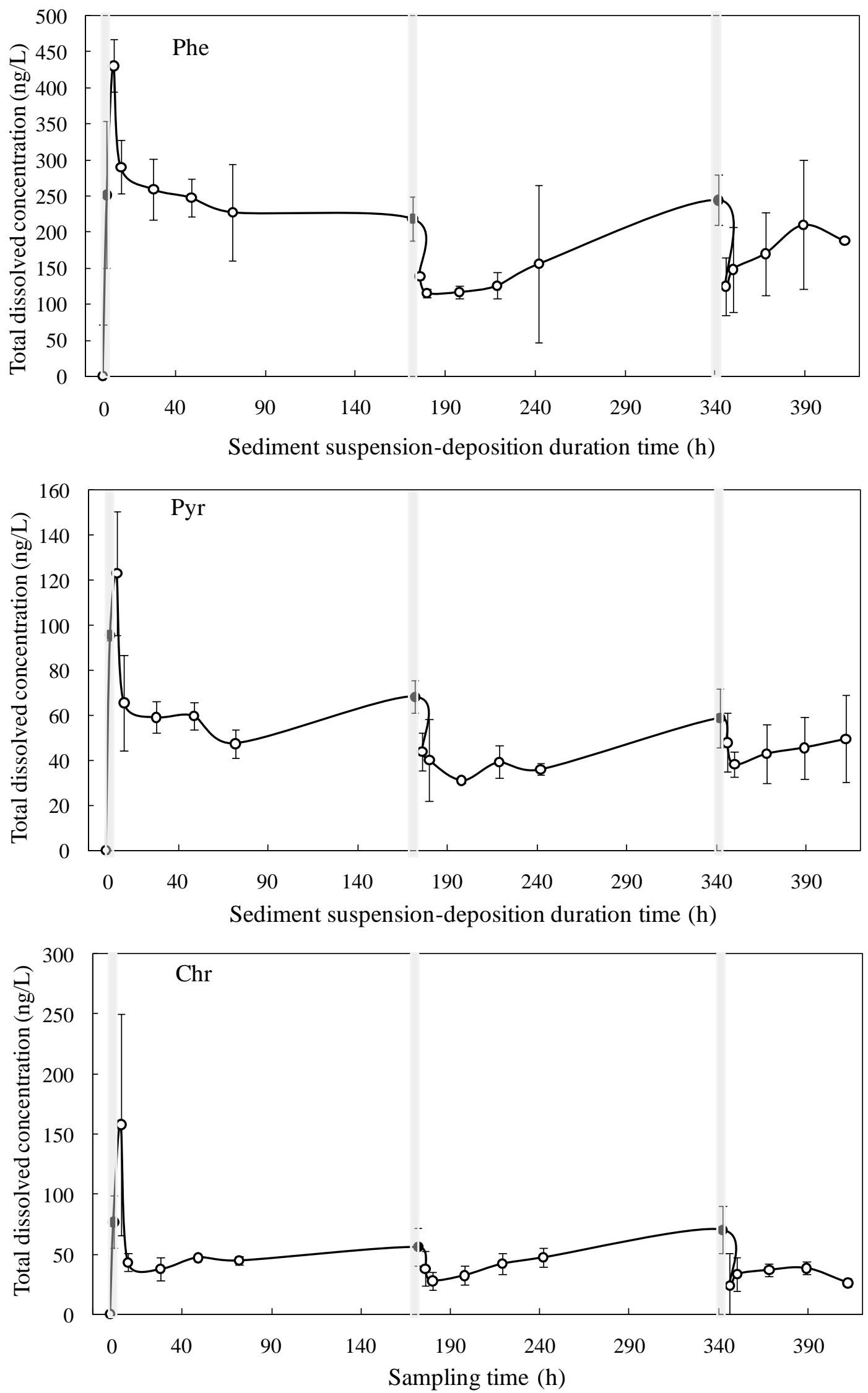

Figure 7 Total dissolved PAH concentrations during recurrent sediment resuspension-deposition events

(Shadow regions stand for the suspension periods; solid circles stand for the samples collected at the end of suspension) 